University of Nebraska - Lincoln

DigitalCommons@University of Nebraska - Lincoln

Faculty Publications: Department of Teaching, Department of Teaching, Learning and Teacher Learning and Teacher Education

Education

2003

\title{
Falling into It: Novice TESOL Teacher Thinking
}

Mark K. Warford

Buffalo State College, warformk@buffalostate.edu

Jenelle Reeves

University of Nebraska-Lincoln, jreeves2@unl.edu

Follow this and additional works at: https://digitalcommons.unl.edu/teachlearnfacpub

Part of the Teacher Education and Professional Development Commons

Warford, Mark K. and Reeves, Jenelle, "Falling into It: Novice TESOL Teacher Thinking" (2003). Faculty Publications: Department of Teaching, Learning and Teacher Education. 117.

https://digitalcommons.unl.edu/teachlearnfacpub/117

This Article is brought to you for free and open access by the Department of Teaching, Learning and Teacher Education at DigitalCommons@University of Nebraska - Lincoln. It has been accepted for inclusion in Faculty Publications: Department of Teaching, Learning and Teacher Education by an authorized administrator of DigitalCommons@University of Nebraska - Lincoln. 
Published in Teachers and Teaching: Theory and Practice (2003) 9(1). Copyright 2003, Taylor \& Francis. Used by permission. DOI: 10.1080/1354060032000049904

\section{Falling into It: Novice TESOL Teacher Thinking}

Mark K. Warford, Buffalo State College, Buffalo, New York, USA, warformk@buffalostate.edu

Jenelle Reeves, Auburn University, Auburn, Alabama, USA (affiliation 2012: University of Nebraska-Lincoln, jreeves2@unl.edu)

Abstract

The authors conducted a qualitative study in order to understand the preconceptions novice TESOL teachers might have about teaching English language. Long interviews were conducted with nine students (six native English Speakers and three non-native speakers (NNS)) enrolled in one of two courses offered in a TESOL teacher education program. None of the participants had experience as an inservice teacher. Inductive analysis of tape transcripts suggested the presence of several conceptual themes discussed in the teacher thinking literature. Findings suggest that novice TESOL teachers, like their more experienced counterparts, have a system of metaphors to conceptualize teaching. The apprenticeship of observation, a notion in teacher thinking that suggests a powerful influence of previous experience in schooling on teachers, was reflected in NNS' sensitivity to the norms of teaching in their country of origin; native English speakers, however, exhibited a relative lack of reflection on their experiences in the language classroom. Both NNS and NS participants expressed a presentistic outlook, borne perhaps, of the socio-political complexities of English language teaching. Novice TESOL teacher thinking also appears to exhibit evolving cognitive foundation that weaves folklinguistic adaptations of expert systems into their approach to teaching. Many participants spoke in the language of constructivism or made reference to terms discussed in SLA research literature. In conclusion, the researchers suggest that this preliminary evidence of metaphors, apprenticeship of observation, presentism, and adaptations of expert systems, constructs a preliminary framework for describing novice TESOL teacher thinking.

Introduction

What do we know about how English language teachers learn to teach? Hammadou (1993) denounces the persistent poverty of research on language teacher education, encouraging 'any and all' areas of inquiry 'to be pursued' (p. 98) be they qualitative or quantitative. Mcneely and Mertz (1991) make the case that pre-service teachers' cognitions may exert a powerful influence on their practice of teaching (see also Lortie, 1975) and represent a neglected area of teacher thinking re- 
search. The Modern Language Journal took an important step toward the advancement of research on language teaching with a special issue on 'How language teaching is constructed' (van Patten, 1997). Freeman and Richards (1996) have contributed the first collection of writings on preservice TESOL teacher preparation. The present study of the preconceptions of novice TESOL teachers represents the next step - the construction of an empirically and theoretically grounded knowledge base for research on novice language teacher thinking.

\section{Review of the Literature}

What we know about language teacher thinking in the language teaching profession may be sorted into macro- and micro-level factors (VanPatten, 1997). The macro view offers a glimpse of the context English language teachers will be inducted into. Crookes (1997) elaborates on the less than professional conditions the typical teacher works under. His review of the literature paints a dark picture of the public school teacher's context: isolation, the lack of opportunity for professional development, competition over scarce resources, poor curricular materials, fiscal constraints and other adverse factors cause teachers to be more focused on basic survival, as opposed to professional needs. While Crookes' (1997) study of the ecology of teaching is insightful, it does not direct itself to the complex world of English language teaching but rather to the context of Western education, in general, and FL (foreign language) pedagogy.

The big picture of English language teaching tends to be discussed in terms of ESL (English as a Second Language) and EFL (English as a Foreign Language) settings, each with its own set of sociopolitical questions. A number of power critiques that specifically address the ESL teaching context have been published in TESOL Quarterly. Two examples illustrate how official approaches to ESL composition and literature classes are ideologically bound. Benesch (1993) argues that ESL, wed to the politics of naturalization, is bound by this phenomenon as students are construed as passive subjects of social assimilation and accommodation. Canagarajah (1993) argues that we are 'ushering in the international hegemony of Western discourses and institutions' (p. 303) in the way we approach the teaching of composition in ESL settings and calls for more pedagogical attention to local knowledge and counter-discourses offered by World English educationists.

The EFL perspective further expands our conception of the phenomenon of English language teaching. Seidlhofer (1999) illustrates how the EFL perspective can enlarge our conception of language teacher preparation. She borrows from Krachu's notion of the Expanding Circle to evaluate the EFL context, within it its own set of sociopolitical baggage. For example, she advocates that EFL teachers approach textbooks with a critical consciousness so they do not, unwittingly, aid in perpetuating social injustice. In particular, she cautions against uncritical incorporation of authentic materials - authentic of what? Seidlhofer is critical of how EFL exhorts 'get(ting) into the skin of the native speaker' and that it is more essential 'to "get into the skin of the foreign learner"' (p. 243), an ability attributed to non-native EFL educators. 
Considering the sociopolitical nature of both ESL and EFL teaching, it comes as somewhat of a shock that Grosse's (1991) survey of TESOL methods course syllabi in American universities found that cultural knowledge was somewhat poorly represented. In addition, the syllabi reflected a more theoretical than a practical orientation. Such results suggest that we may not be adequately preparing future English language teachers to cope with the sociocultural factors they will encounter in their teaching careers.

What We Know on a Micro-level: Coherence Systems, Folklinguistic Theories, and Metaphors

What about English language teaching up close? If we accept that the macro-level condition of English language teaching can be essentially divided into ESL and EFL contexts, the micro-level view is somewhat more difficult to capture. In the past several years, there has been increased research interest in discovering how the individual language teacher develops a practice of L2 teaching. Kinginger (1997) concerns herself with the ways teachers take elements of their experiences and milieu and weave a coherence system, a notion first advanced by Linde (1993). Linde describes the teacher's coherence system as a 'popular version of expert theories and systems' (p. 18). Coherence systems are governed by the dynamics of causality and continuity in life experiences. They are governed by the assumption that we carry 'life stories' that are the sum of all of our experiences as members of a social system. Journals, bios and autobiographies, and interviews are among the methods, which can elicit such knowledge. Interviews in particular can be used to construct narratives, chronicles and explanations of experience. Kinginger (1997), in developing Linde's notion of the coherence system (1993), stresses the important role of a dynamic relationship between practitioners and expert systems derived from theoretical research and more popular varieties of expert systems, known as folklinguistic theories (citing Miller \& Ginsburg, 1995) [1].

Metaphor also plays a central role in the coherence system (Kinginger, 1997). Lakoff and Johnson (1980, cited in Miller \& Ginsburg, 1995 and Kinginger, 1997). Metaphors are windows into 'conceptual systems' (Lakoff \& Johnson, p. 4). They can also describe social systems and therefore, might be of help in developing an approach to syntagmatic data analysis. Types of metaphors include orientational metaphors, which are spatial and ontological metaphors, which make sense of experiences. There are also metaphors of objects and substances, which categorize, group, and quantify experiences.

Metaphors enable teachers to structure experience into coherent wholes. Ryan (1996) has studied EFL teachers' use of metaphors to express a range of views on the nature of the target language's culture. Some metaphorical groupings that emerged include: objects, high culture, and historical view. Interviews with 24 Mexican EFL teachers and 6 native speaking teachers, audiotaped classroom observations, and relevant documents enabled Ryan to explore these teachers' experiences with language learners, as well as their personal conceptions and beliefs 
about the TL (target language) culture. Quilting was the most common metaphors used to describe American culture.

One of the few studies of preservice L2 teachers investigated narratives, interviews, and other documents for metaphorical themes. Oxford, Tomlinson, Barcelos, Harrington, Lavine, Saleh, and Longhini (1998) organized these themes around four philosophical orientations: social order, cultural transmission, learner-centered growth, and social reform. The social order orientation included teachers who valued 'the well being of society' (p. 13) as a major pedagogical concern. Under this perspective, teachers tended to see themselves as: manufacturers, competitors, hanging judges, doctors (or error killers), or as 'mind and behavior controllers' (p. 14). The cultural transmission category perceived the teacher role as one of a conduit or repeater. Under the learner-centered view, teachers were depicted as nurtures, lovers or spouses, scaffolders, entertainers, or delegators. Social reforming teachers, according to the authors, saw themselves as acceptors/learning partners.

Teacher Thinking Research: Entering the World of Teaching through Teacher Cognition

The theoretical framework that guides the present study lies in the field of teacher thinking research, a line of inquiry that focuses on the social and cognitive forces behind the decisions teachers make. According to Freeman (1996), teacher thinking inquiry began in the late 1960s and early 1970s with a narrow focus on discrete teacher behaviors and the 'student outcomes' they produced (p. 736) toward macrolevel concerns of teacher accountability. Freeman describes how this approach tended to neglect the cognitive variables of individual teachers. Both Freeman (1996) and Mcneely \& Mertz (1990) cite Lortie (1975) and Elbaz (1983, in Freeman 1996; 1991, in Mcneely \& Mertz, 1990) as influential figures behind the paradigm shift to a more cognitive focus. An early theme of teacher thinking research was that of 'teacher as decision-maker' (Freeman, 1996). Under this focus, Freeman (1996) describes how this first generation of research on teacher cognition looked at data within teacher narratives. This representational approach, according to Freeman, focused on 'what it [the data] says and not necessarily how it says it' (p. 734). In other words, the language, itself, was not seen as important as the underlying cognitions it represents.

Building on this foundation that assumes that qualitative data collected on teachers 'can represent teachers' worlds' (p. 743), Freeman (1996) describes an emergent presentational approach to teacher thinking research methodology that integrates both socio- and psychological analytical approaches. The presentational view of teacher thinking assumes a sociological view of language analysis, resting on the theories of linguists such as Gee (1990) and Bakhtin (1981). The linguist's focus on 'what is said in contrast to what is not said, and what is said in contrast to what precedes and follows it' (Freeman, 1996, p. 744) is an added focus in this approach to data analysis. Freeman refers to the former as paradigmatic concerns and the latter 
as syntagmatic concerns. While the representational view of data analysis concerns itself with categories represented in the language, the latter deals in uncovering 'coherence' and 'context' with in language presentation (Freeman, p. 746). An assumption behind syntagmatic considerations in linguistic research is that 'language depends on a speech community to create and sustain meaning' (Freeman, p. 745). Another assumption underlying the syntagmatic view of teacher language data is that 'the voice is social and not individual' (Bakhtin, 1981). In other words, the syntagmatic view of teacher language challenges teacher thinking researchers to adopt a 'social view' of language as 'a fabric of relationships that links people, not a vehicle by which individuals communicate meanings' (Freeman, p. 749). Communities in teaching internships include the triad (the intern, the mentor teacher, and the university supervisor), as well as their respective groups: i.e. the community of interns, the community of mentor teachers, or the community of university supervisors. The value of the presentational approach is that it lives up to the challenge in teacher thinking research to take them at their word by respecting the social discourses that are represented in the words of individual teachers. At the present, the method is new and untested; it remains to be seen that the interplay of paradigmatic and syntagmatic analysis is of use in studies of preservice teachers.

In research on teacher thinking, a variety of concepts have emerged to illuminate the black box of teacher cognitions. Terms include: apprenticeship of observation, presentism, and practical knowledge. In research on language teacher thinking, the notion of teacher coherence systems has been advanced. In his survey study of teachers in a Massachusetts suburb, Lortie (1975) encountered what he refers to as the apprenticeship of observation. As Lortie puts it, 'their principal teacher has been experience' (p. 79). Years of 'passive observation' (p. 61) as classroom students exert, according to Lortie, a powerful influence over novice teachers' preconceptions about teaching. He further argues that 'the lack of potency in the formal socialization system means that earlier conservative influences ... are not systematically offset in the course of induction' (p. 81). Lortie's description of the fragmented, isolated ecology of school teaching suggests that novice teachers' introduction to teaching will be marked by endemic uncertainty. According to Lortie the ease of entry into the profession 'exacerbate(s) rather than alleviate(s)' (p. 161) this problem. He argues that many novice teachers face a " sink or swim" situation' (p. 237) in their initial experiences in the profession. In reviewing the history of teaching in America, Lortie also notes what he refers to as the primacy of presentism in the teaching profession, which describes the lack of perspective and reflection within the custodial culture of mainstream teaching. A 'present-orientation' also reflects the lack of material rewards for teaching, and that 'few beginning teachers intend to stay very long' in the profession (p. 101).

Elbaz (1983) advances the notion of the teacher as an active agent who weaves together a practical knowledge base that guides her decision-making in various teaching situations. What she refers to as practical knowledge involves the dynamic of observation, comparison, and trial-and-error in teaching. Practical knowledge is a personal as well as social phenomenon, and the teacher is the ultimate pro- 
fessional authority. Dimensions of practical knowledge include experience, attentiveness, and level of interest. Her case study of 'Sarah' is a 'holistic study of ... (the) person in relation' (p. 10) and, therefore, takes a social contextual view of teaching. Five interviews and two observations were conducted in order to probe various aspects of practical knowledge: knowledge of self as source, as being in relation to others, and as individual. In terms of social variables, practical knowledge was also investigated according to the classroom, the political frame, the process of building social setting, and breaking down the subject matter into teachable skills. Elbaz found that practical knowledge had both theoretical and situational dimensions. Sarah's experience of teaching, according to Elbaz, could be divided into three components: time (as commodity), space (the process of integrating), and 'tension of consciousness' (which involves the distillation of rules and principles in practice) (p. 137). Elbaz also found that practical knowledge, as demonstrated by 'Sarah' is worked out through 'image rather than through argument' (p. 151).

Lortie's (1975) and Elbaz' (1981) studies serve as a foundation for an understanding of the teacher that transcends the traditional view of teaching as conformity to a technical system (i.e. Hunter, 1984). Their work has forced a critical confrontation with the primacy of the individual teacher's experiences and thinking, internal forces that shape decision-making, and ultimately, professional practice.

\section{Four Studies Relevant to the Study of Novice English Teachers' Preconceptions}

In addition to Kinginger's journal study, four additional studies culled from the professional literature are particularly relevant to the study of cognitive constructs that English language teachers might carry into their practice of teaching. Freeman (1991) conducted a case study of four beginning foreign language teachers for his doctoral dissertation. His study follows the participants through two subsequent summer inservice programs. Freeman finds tremendous variation among participants at beginning, though three themes emerged: firsthand experience with L2 was better than instructional experience; all four fell into teaching accidentally; they were also more content-focused at the beginning of the program. In addition, they had a tendency to rely too heavily on the textbook and to see the students as a class rather than as individuals. At this stage, Freeman found support for Lortie's (1975) notion of an apprenticeship of observation. After the first summer, Freeman noted a wide variety of responses among the four participants, though each expressed a referential perspective focused on their peers. Gathering new ideas and approaches led to the struggle for cognitive mastery of new teaching discourses and their application in practice. At this stage, they were in the process of deepening their inquiry while trying to reach a comfort zone within the new concepts they had attained.

During the subsequent year of teaching, all four showed less enslavement to the text and a sense of trying to balance 'spontaneous and managed interaction' ( $p$. 246) with students. They began to consider the balance between uniformity and 
individuality in instruction and questioned whether there might be more that the students could take on in developing ownership of the learning process. After the second summer program, the teachers had greatly expanded their capacity to visualize instruction and had obtained a richer, more complex understanding of teaching. While Freeman's study focuses on language teachers, it may be argued that the ESL/EFL context of the present study differs substantially from a United States-based FL context. Also, the participants had already begun teaching, which limits the generalizability of the studies findings to the present context.

In preservice teacher education, Mcneely and Mertz $(1990,1991)$ conducted a similar long-term study involving 10 preservice teachers that began in advance of the internship and continued through the internship year. Though the study tends to treat the discipline areas (English and foreign language) as relatively unimportant variables, the study uncovers the interns' preconceptions regarding teaching, their confidence and idealism at the beginning of the internship, and the creeping negativism that results when their preconceptions crash headlong into the reality of the classroom. Teacher cognitions captured in journals and lesson plans reveal essentially two distinct voices. The first, which represents the idealization of the teaching experience beams with optimism and careful preparation. The second voice, the voice of the field-weary teacher suggests a surrender to status quo conformity to a reductive, custodial view of teaching that reflects the worst aspects of inservice teaching culture. The study raises significant questions regarding the actual impact (or lack thereof) of teacher education. It also lends some weight to Tedick, Walker, Lange, Paige, and Jorstad's (1993) warning that

failing some redevelopment of teacher education programs in the departments, schools, and colleges of education ... school districts and other consortia will do the development for us. (p. 35)

According to Mcneely and Mertz (1991), research on the preservice side of teacher development is still relatively new and inconclusive.

Two recent studies investigate English language teacher thinking. Duff and Uchida (1997) offer one of the few studies of EFL teacher thinking. This qualitative study focuses on two questions about EFL teachers, one exploring the 'sociocultural identities, understandings, and practices' (457) over a period of time, the other focusing on the factors that affect fluctuations in those phenomena. Ethnographic and participant-observation methods were used to gather data. The authors' analysis of the data collected on four EFL teachers (two American, two Japanese) identified four aspects of EFL teachers' sociocultural identities and classroom practices: complexity of identity and class representation; interpersonal/intercultural connections; control of identity; and disjunctures between beliefs and practices. Golombek (1998), building on Elbaz' notion of practical knowledge, triangulated class observations, stimulus recall reports and interviews in order to better understand the practical knowledge systems of two ESL teaching assistants enrolled in a teacher training program. Results of the study underscored tensions 
related balancing and scaffolding in the classroom. These tensions, revealed by the participants, were not just technical in nature, but included moral and affective dimensions, as well.

The literature suggests that research on novice TESOL educators' preconceptions about teaching tend to be explored on either a macro or micro level. Freeman's (1996) preliminary investigations into language teacher thinking suggest that this may not be an either/or decision. That is, a micro level study, informed by a sociocognitive analytical approach, might unlock social discourses in the language of individual teachers. A look at some representative samples from the literature shows that what we know about preservice TESOL teachers' preconceptions about teaching is scattered and superficial. Significant themes that may be of relevance to our study may be sorted into macro-and micro-level considerations. On the macro-level, the socio-politics of teaching English language have warranted attention - both in EFL and ESL settings. On the micro-level, what does novice (preservice) TESOL teacher thinking look like? Based on our review of the literature, the researchers determined the coherence system (Linde, 1993; Kinginger, 1997) to be a useful organizing construct, with sub-elements possibly including:

- Folklinguistic theories (Miller \& Ginsburg, 1995)

- Metaphors (Lakoff \& Johnson, 1980)

- Expert systems (Kinginger, 1997)

- EFL vs. ESL dimensions (Freeman, 1996; Duff \& Uchida, 1997)

Still, a more in-depth investigation of what English language teaching means to these individuals, from their perspective, is lacking. Two major questions linger: 'What, if any, preconceptions about teaching do preservice TESOL educators have?' and 'How useful are the constructs raised in the literature in building a framework for understanding these preconceptions?'

\section{Participants}

In order to better understand the preconceptions novice TESOL teachers have of teaching, the researchers selected participants from two classes in a TESOL teacher preparation program during the Fall Semester, 1999, at a major Southeastern University. A total of nine participants selected for the purpose of conducting long interviews. This number meets McCracken's (1988) expectations for a minimum number of interviewees (eight). While some may argue that nine represents a rather small sample, we maintain that, as a qualitative study, this number was sufficient in order to paint a substantial portrait of novice TESOL teacher thinking. We make no pretensions of generalizability to the larger population, in the quantitative sense.

Criterion for participation was an interest ESL/EFL teaching, preferably a desire to enter a career in ESL/EFL teaching. All participants were to be novice educators, having no or limited teaching experience. A total of nine participants were 
interviewed: five women and four men. Both native and non-native speakers of English participated: six native speakers and three non-native speakers. Participants' teaching experiences ranged from as limited as a one-month job as an EFL tutor (this was the only participant not enrolled in the TESOL teacher preparation program) to one semester's experience as a student teacher in ESL. Two participants with some degree of in-service teaching experience were included in order to see if there might be any qualitative differences relevant to the presence or absence of some sort of initial teaching experience. No participants were without some degree of EFL/ESL teaching experience; only one had held a sustained full-time TESOL teaching position (one summer). All participants had themselves been language learners at some time in their lives. The range in language learning experiences started from as little as two years in high school to ten plus years through college.

\section{Methodology}

The present study makes the assumption that inquiry grounded in the particular may add substance to our current understanding of the meaning of how TESOL teacher thinking develops. The researchers attempted to cast the widest possible net of content in order to better understand - from the preservice TESOL educators' own perspective - what English language teaching means to them in this early stage of their professional development.

A paradigmatic assumption behind this approach is that Constructivist theory can deepen research into TESOL teacher thinking. Within the field of L2 education, a Constructivist approach appears to be gaining acceptance (Warford, 1998). In a 1997 issue of the Modern Language Journal, Nyikos and Hashimoto (1997) cite Piaget (Russell, 1993) and Vygotsky (1998) as laying the groundwork for a Constructivist epistemology for L2 educational research in which knowledge is seen as constructed through a combination of subjective (individual) and intersubjective (social) processes. This approach, which echoes Freeman's (1996) interplay between paradigmatic and syntagmatic analysis, has not been widely implemented, but it provides a framework for exploring novice TESOL teachers' subjective assumptions about the profession, as well as the intersubjective dynamic that may result from interaction with peers and professors.

A method appropriate to these assumptions and to the goal of the study is that of the long interview, as advanced by Grant McCracken (1988). McCracken argues that a major benefit of this approach is the possibility of a more authentic, emic view of a study participant's feelings and perceptions: 'The method can take us into the mental world of the individual and glimpse the categories of logic by which he or she sees the world.' (p. 9). Since both of the authors are L2 educators pursuing careers as language teacher educators, we have some personal insights into the training and development of language teachers; this vantage point has its disadvantages. According to McCracken: 
Intimate acquaintance with one's own culture can create as much blindness as insight. It can prevent the observer from seeing cultural assumptions and practices. The long interview presented here is designed to take advantage of the opportunity for insight and minimize the dangers of familiarity. (p. 12)

In response to this issue, McCracken (1988, p. 29) proposes the establishment of analytic categories, (pp. 29-48), through representative review of the literature. This process helped us develop crucial distance from the subject matter and set an initial framework for an interview instrument (p. 32).

Following McCracken's guidelines for an interview guide, we organized a list of general questions that covered the key points suggested in the literature. Mcneely and Mertz' (1991) study was determined to be the most useful in that the questions asked in their interviews captured the thoughts of prospective teachers at the very beginning of their teacher education program. For this reason, the researchers adapted and incorporated several of the questions asked in that study in developing an interview guide for the present study.

Following suggestions advanced by McCracken, Grand tour, tone setting, and background questions, as well as guarantees of confidentiality and anonymity were followed by some general questions about their experiences in language education. Participants were also asked about any emerging ideas they might have about TESOL teaching, as well as any emergent expectations they might have in anticipation of a career in English language teaching. While the interview guide provided a common framework, the primary goal of the interviewers was the creation of an atmosphere that encouraged interviewees to tell their stories in their own words. All questions on the interview guide were asked of the interviewees, often presenting themselves within the natural flow of the interviewee's discourse; however the interviewers also allowed-even encouraged - participants to express ideas and opinions beyond the bounds of the questions asked in order to arrive at a more emic understanding of novice TESOL teacher thinking.

Each interview concluded with a validity check, inviting the participant to add anything else they would like to share, the opportunity to call if they had anything to add or correct from the interview record, as well as review the interview transcript (see McCracken, 1988, pp. 34-35). None of the participants took advantage of this offer.

\section{Data Analysis}

In analyzing the data, tapes of the interviews (each approximately a half-hour in length) were carefully transcribed. Following McCracken's (1988) guidelines, each transcription was analyzed carefully in its own right for internal themes prior to checking for themes that emerged across the transcripts. Data sections were coded first according to which question a particular section pertained to and then analyzed according to those designations. The researchers then highlighted and categorized the participants' use of metaphors. Some limited phone and e-mail fol- 
low-up was conducted in order to verify the strength of a particular theme across participants. Generally, this stage of the analysis is what Freeman (1996) would refer to as paradigmatic. In order to uncover syntagmatic themes, the language of the transcripts was coded for evidence of folklinguistic discourses. Following the analysis procedure, the researchers were able to construct a working model of the novice TESOL teacher coherence system.

Results

As noted before, the transcriptions of the interviews were coded inductively for conceptual themes culled from the literature: metaphors, the apprenticeship of observation, folklinguistic theories (defined by the researchers as 'teacher adaptations of expert theories/systems'), and presentism. With regard to the metaphors used by participants, the data essentially suggests three categories: metaphors for deciding to enter the English language teaching profession; metaphors for English language; and finally, metaphors for TESOL teaching. The most prevalent metaphor used by participants was elicited in response to the question: 'What made you decide to become an ESL/EFL teacher?' The majority of participants responded with some version of the phrase: 'I fell into it.' This Alice-in-Wonderland, falling down a rabbit's hole style of discovery was expressed by every participant some degree. Related expressions included: 'out of the blue,' 'fell into my lap,' 'luck,' 'haphazard,' and 'in limbo' in describing the career decision process.

A second major metaphor employed by participants in this study was that of the English language as a form of power. Several non-native speaking, EFL-bound participants recognized English as an international language, its acquisition as necessary to gain employment and financial prominence. One participant described English language ability as 'ammunition.'

A third category includes metaphors for English language teaching. The notion of 'having one's heart in it' was, at times, contrasted with 'building a wall around oneself', projecting an image of teacher 'as God' or 'blindness' to the needs of one's students. Another recurrent metaphor was that of English language teaching as chameleon. Visualized ESL/EFL jobs and teaching situations were described as situational. Participants described their preconceptions of future careers as dependent on circumstances beyond their control: economy, foreign governments, school peculiarities, etc. These metaphors not only provided insights into participants' preconceptions of ESL/EFL teaching, they were clearly integral components of participants' coherence system frameworks, as Kinginger (1997) suggests.

A second theme concerns the way participants connected (or did not appear to connect) their experiences as learners to their experiences as teachers. Though teachers, as Lortie (1975) asserts, have a long apprenticeship of observation as students from which to draw preconceptions about the profession, evidence of this phenomenon was more prevalent among non-native speakers who were considering returning to their homelands to teach English (EFL). In visualizing themselves in the role of teachers, the three NNS appeared more likely to have access to their own language 
learning experiences than their native-speaking counterparts, several of whom had particular difficulty remembering their language learning experiences in significant detail. This may be a function of the fact that the NNS, being in an L2 context, are still in the language learning experience. Two of the three NNS were so profoundly marked by their EFL language learning experience that they found it difficult to envision teaching any other way; this is in spite of the fact that they were favorable to the more communicative teaching methods they experienced here in the U.S. In both cases, the dominant mode of instruction is grammar-based instruction with little L2 spoken in the classroom. One Japanese participant, states:

I think probably I'll teach almost same way cause, um, it's difficult to use only English in Japanese classrooms, so, almost same.

Another, from Thailand, feels this formal grammar based approach is so ingrained, that the only way to avoid falling back on it is to teach advanced level English at a university. Following is an insight that may have application to FL teaching, in general:

...in Thailand I believe that one reason most teachers do not teach their classes in English is because they're afraid of making mistakes, grammar mistakes, it's going to make them, you know, lose face. Imagine, imagine yourself as a respected teacher, if you keep making mistakes you will not be respected.

Here in the United States, an emphasis on talking about the L2 (in L1) rather than talking in the language, has been linked to lack of L2 language ability (Lafayette, 1993). The prominence of this pedagogical perspective may exert a powerful conscious or unconscious influence on the future FL teacher, a factor that warrants closer attention.

Several budding folklinguistic theories also emerged from the data. Two were derived from expert systems that perhaps were presented during the students' coursework. Syntagmatic analysis of the transcripts revealed the prominence of what the researchers have decided to call 'constructivese', a language of 'learnercenteredness' that permeated the participants' speech. The respondents, in referring to the qualities of an ideal language teacher, almost unanimously agreed that the English language teachers should be learner-centered in their approach. The reference also came up in other contexts such as discussing what their teaching experience would be like. Kinginger (1997) found similar speech patterns in the journals of teacher education students. Oxford et al.'s (1998) categories, mentioned earlier, provide a useful framework for categorizing this language of learner-centeredness noted in the transcripts:

- Nurturing: help them 'express opinions;' 'create a relaxed, comfortable atmosphere;' 'atmosphere conducive to learning'

- Teacher as lover/spouse: 'empathy' / being 'intuitive;' being a 'friend;' 'compassion;; 'understanding' 
- Scaffolding: 'put myself in their shoes;' 'be aware of students' background,' 'be adaptable to students' needs;' 'sensitive to learning styles'

- Entertaining: 'make the class interesting'

- Delegators: 'just getting them more involved in their own learning, and not just have someone else kind of responsible for their learning.'

A general commonality is a Constructivist epistemology: knowledge is created in the individual; ergo, the learner should be the locus of instruction. In addition, there was some limited evidence of a SLA influence with scattered references to: fossilization, Stephen Krashen, and the motivation of language learners.

In visualizing a career in TESOL, the participants expressed a unique variety of presentism (Lortie, 1975). This way of seeing their professional context expresses itself in the data in essentially three facets. One influence would appear to be the coursework, which apparently sensitizes these students to the sociopolitical complexities of English language teaching at home or abroad. Very few, from the least to the most experienced dared to visualize, with confidence and clarity, what their inservice experience might be like. This is in stark contrast to the naïve, egocentered idealism of the preservice teacher education students that Mcneely and Mertz (1991) interviewed, as there is a sense of deference to, or perhaps trepidation about the complexities of the type of teaching these students are preparing for. As one NNS put it: 'I just think there's too many issues I did not know before.'

Another facet of presentism came from a sense of one's own life experience as being serendipitous, a philosophy connected to this 'falling into' sense of their professional life. One NNS felt that he jinxed any opportunities by planning for them, another NS candidate, a devout Christian expressed this as the experience of imposing her plan on the plan she felt God had in mind for her. In the following excerpt, she is describing the experience of not being able to find a job as a certified recreational therapist, this after committing time and energy to getting certified:

You see, there's two plans-Plan A is God's plan, the only plan, and Plan Bis when we go off on our own and we think we're invincible and we can figure it out ourselves. And I was on Plan B, and so it was very devastating when I couldn't find a job because it wasn't working into my plan. And so I've learned just to let go and give it all to God because I don't have control.

This participant's philosophy of life revolves around the New Testament's Great Commission, an Evangelical Christian outlook that may be prominent in the teacher thinking of some who pursue English language teaching an extension of their religious convictions. Whether or not this profile is common on a global scale is largely a matter of speculation; however, in the Southeast United States, it is fairly common. This evangelical variation on presentism, which focuses on what God wants one to do in the present, was conveyed in expressions like 'one day at a time' or 'it's in God's hands'. As this participant puts it: 
We are disciples ... and until every tongue, tribe, and nation has heard the Word, Christ is not going to return. And my view of that is I'm a tourist passing through here. This isn't my home. Heaven is my home, and that's where I want to be. And so I look at ESL as a way to go out, whether it be here in the United States, because there are so many internationals coming here now, we have a mission field in our own back yard. Or going abroad and using ESL as a way to minister to people. That's the way I see it, for myself.

Putting it all together, then, we find that an initial model for novice TESOL teacher coherence system should recognize the following framework:

- The use of metaphors to convey ideas about English language, TESOL teaching, and the choice of TESOL as a vocational path.

- The differential effect of the apprenticeship of observation on EFL/ESL contexts.

- Folklinguistic theories adapted from expert systems like Constructivist theory.

- An expression of presentism that is unique to the TESOL context and is based on: recognition of the socio-political complexities of the profession; and a dayby-day outlook on life that may come from either a sense of interpreting one's experience as serendipitous or Evangelical Christianity.

\section{Conclusion}

Before discussing any conclusions that might be reached based on the present study, it is important to clarify several limitations. The first limitation deals with the rather broad definition of 'novice TESOL teacher' the researchers were willing to accept. The addition of two participants with some initial experience in leading their own class did appear to impact the overall amount of output in the interview, as these interviews produced the longest transcripts. Other than a difference of content, the researchers were unable to find qualitative differences between these two participants and the others. An important issue that needs to be considered is the appropriateness of long interviews in L2. Would it be appropriate to have an interpreter present for the duration of the taping? It would seem that such circumstances would render syntagmatic analysis of language presentation meaningless. Also, should long interviews be allowed to stand on their own as valid representations of teacher thinking? Triangulation of journal analyses and scripting of classroom visitations might add depth and precision to data collection and analysis.

In its attempt to explore the preconceptions of novice TESOL teachers, the present study has tested some constructs in the literature that were hypothesized to be useful in adding conceptual clarity to the exploration of this phenomenon. The term coherence system, and its components compiled from the literature are indeed useful in this line of inquiry and merit further study in order to determine the broad range of variables that might underlie the thinking of students preparing for a career in English language teaching. Do these constructs comprise an exclusive, authoritative way of seeing? Probably not. The goal was not to engage in a fishing expedition, 
or self-fulfilling prophecy. We are content to have provided some preliminary empirical validation of their value in inquiry into TESOL teacher thinking.

The study also endeavored to synthesize a methodology for the investigation of novice teacher thinking from the work of Freeman (1996) and McCracken's (1988) vision for the long interview technique. Both paradigmatic and syntagmatic approaches to data analysis (Freeman, 1996) are equally valuable. The latter may be particularly crucial in that it preserves the integrity and primacy of language as representative of a system of thinking. This syntagmatic line of analysis may also be the most elusive, dependent on the researcher's ability to correctly discern social discourses underneath a participant's language flow. Perhaps some general guidelines for integrity in use of this line of analysis can and should be developed.

In answer to the question, 'What, if any preconceptions do novice TESOL teachers have of teaching?' this study would suggest that there is evidence of preconceptions and that these preconceptions suggest the rudiments of a coherence system based on four components: a system of language teaching-related metaphors, a greater influence of an apprenticeship of observation among NNS planning to teach in and FL setting, various folklinguistic theories based on expert systems encountered in coursework, and a unique presentism that may be a function of the complexity of the TESOL profession.

How these factors play out in actual teaching, we cannot be sure. Unlike studies such as those conducted by Elbaz $(1981,1983)$ and Golombek (1998), and Schön (1987),we have no way of measuring how these rudiments of professional knowledge express themselves as what Schön (1987) refers to as knowledge in action. Where the preservice teachers interviewed in this study go from here, both in their professional life and their thinking is a question that the researchers hope to investigate in future studies. What, then, can be gleaned from this study for practice in TESOL teacher preparation? Results suggest that the assumption that TESOL teacher education students do not enter with a tabula rasa. This does not mean, however, that the coherence systems that they are nurturing exert an omnipotent influence on their actual practice of teaching. At the very least, these preconceptions ought to be addressed openly in teacher education courses through discussion or written reflection.

Note: [1] Miller and Ginsburg (1995) investigated folklinguistic theories of language learning as evidenced among American college students abroad in Russia. The authors observed that students did not make full use of the opportunities they had for Russian language acquisition, in part due to their tendency to formalize conversations around their instructed language learning experiences. This was indicated in a review of 80 diaries and 20 audio recordings. The students' theories of language learning, based on formal instruction, included a dogmatic adherence to the notion of a formal language as absolute truth, evidenced in their tendency to impose order and focus on form. In terms of the folklinguistic theory underlying their approach, the authors describe it as the traditional mind as container approach to language learning (citing Lakoff \& Johnson, 1980). 


\section{References}

Bakhtin, M. (1981) The Dialogic Imagination (Austin, Texas, University of Texas Press). Benesch, S. (1993) ESL, ideology, and the politics of pragmatism. TESOL Quarterly 27: 705-715.

Canagarajah, A.S. (1993) Up the garden path: second language writing approaches, local knowledge, and pluralism. TESOL Quarterly 27: 301-310.

Crookes, G. (1997) What influences what and how second and foreign language teachers teach? Modern Language Journal 81: 67-79.

Duff, P.A. \& Y. Uchida (1997) The negotiation of teachers' sociocultural identities and practices in postsecondary EFL classrooms. TESOL Quarterly 31: 451-486.

Elbaz, F. (1981) The teacher's 'practical knowledge': report of a case study. Curriculum Inquiry 11: 43-71.

Elbaz, F. (1983) Teacher Thinking: A Study of Practical Knowledge (New York: Nichols).

Freeman, D. (1991) Doing the Same Things Differently. Unpublished doctoral dissertation, Harvard University.

Freeman, D. (1996) 'To take them at their word': Language data in the study of teachers' knowledge, Harvard Educational Review 66: 732-761.

Gee, J. (1990) Social Linguistics and Literacies: Ideologies in Discourses (Philadelphia, Pa.: Falmer Press). Golombek, P.R. (1998) A study of language teachers' personal practical knowledge. TESOL Quarterly, 32: 447-464.

Grosse, C.U. (1991) The TESOL methods course. TESOL Quarterly 25: 29-49.

Hammadou, J.A. (1993) Inquiry in language teacher education. In: G. Guntermann (Ed.), Developing Teachers for a Changing World, Chapter 4, pp. 76-104. ACTFL Foreign Language Education Series. (Lincolnwood, Ill.: National Textbook).

Hunter, M. (1984) Knowing, teaching, and supervising. In: P.L. Hosford (Ed.) Using What We Know about Teaching (Alexandria, Va.: ASCD).

Kinginger, C. (1997) A discourse approach to the study of language educators' coherence systems. Modern Language Journal 81: 6-14.

Lakoff, G. \& M. Johnson (1980) Metaphors We Live by (Chicago, Ill.: University of Chicago Press).

Linde, C. (1993) Life Stories: The Creation of Coherence (New York: Oxford University Press).

Lortie, D. (1975) Schoolteacher: A Sociological Study (Chicago, Ill.: University of Chicago Press).

McCracken, G. (1988) The Long Interview. Qualitative Research Methods Series 13. (Newbury Park, Calif.: Sage).

Mcneely, S.R. \& N.T. Mertz (1990) Cognitive constructs of pre-service teachers: research on how student teachers think about teaching. Paper presented at the Annual Meeting of the American Educational Research Association, Boston, Mass. (ERIC Document Reproduction Service No. ED 322 116).

Mcneely, S.R. \& N.T. Mertz (1991) Cognitive constructs of pre-service teachers: how students think about teaching before formal preparation. Paper presented at the Annual Meeting of the American Educational Research Association, Boston, Mass. (ERIC Document Reproduction Service No. ED 331 810).

Miller, L. \& R.B. Ginsburg (1995). Folklinguistic theories of language learning. In: B. Freed (Ed.), Second Language Acquisition during Study Abroad, pp. 293-315. (Amsterdam: John Benjamin).

Nyikos, M. \& R. Hashimoto (1997). Constructivist theory applied to collaborative learning in teacher education: in search of ZPD. Modern Language Journal 81: 506-517.

Oxford, R.L., S. Tomlinson, A. Barcelos, C. Harrington, R.Z. Lavine, A. Saleh \& A. Longhini (1998) Clashing metaphors about classroom teachers: toward a systematic typology for the language teaching field, System 26: 3-50.

Russell, D.R. (1993) Vygotsky, Dewey, and externalism: beyond the student/discipline dichotomy. Journal of Advanced Composition 13: 173-197.

Ryan, P.M. (1996) Sociolinguistic goals for foreign language teaching and teachers' metaphorical images of culture. Foreign Language Annals 29: 571-586.

Schön,D.A. (1987) Educating the Reflective Practitioner: Toward a New Design for Teaching and Learning in the Professions (San Francisco, Calif.: Jossey-Bass).

Seidlhofer, B. (1999) Double standards: teacher education in the expanding circle. World Englishes 18: 233-245. 
Tedick, D.J., C.L. Walker, D.L. Lange, R.M. Paige, \& H.L. Jorstad (1993) Second language education in tomorrow's schools. In: G. Guntermann (Ed.) Developing Teachers for a Changing World, pp. 43-76. ACTFL Foreign Language Education Series. (Lincolnwood, Ill.: National Textbook).

VanPatten, B. (1997) How language teaching is constructed: introduction to the special issue. Modern Language Journal 81: 1-5.

Vygotsky, L.S. (1998) Mind in Society: The Development of Higher Psychological Processes (A. Kozulin, revised translation, Ed.) (Cambridge, Mass.: Harvard University Press).

Warford, M. (1998) The Status of Qualitative Research in the Field of Second Language Acquisition. Unpublished manuscript. The University of Tennessee.

Appendix A: Interview Guide Used in Study

Preconceptions of Novice ESL/EFL Teachers

Question 1: Tell us a little bit about yourself.

a. Where are you from?

b. What's your educational background?

c. Have you had any coursework in ESL/EFL methods or theory? If so, what, if any, impact have these courses had on your views of ESL/EFL instruction? If not, what do you expect to learn about ESL/EFL teaching from these courses.

d. What, if any, prior teaching experiences have you had? (including ESL/EFL and other subject areas)

Question 2: Describe your own experiences as a second/foreign language learner.

a. Where did you study? For how long?

b. Describe your school(s).

c. What were your teachers like?

d. Overall, how would you evaluate your language experience(s).

Question 3: Do you plan to teach English here (in the U.S.) or abroad?

a. Where, specifically, are you planning to teach in U.S./abroad. (What state/region? What country?)

b. How did you choose this area?

Question 4: How did you decide to become an English language teacher?

a. Was there a particular person/teacher/experience that influenced your decision?

Question 5: Have you given any thought to what teaching ESL/EFL will be like?

a. What do you think it will be like when you become a teacher?

b. Have you thought about ways it will be similar to or different from your previous language learning experiences? (If so, please describe.)

Question 6: What qualities would the ideal language teacher possess?

a. Please elaborate (quality by quality).

Wind down: Thank participant, ask if there is anything they would like to add and that, if they would like to add or change their responses, they are welcome to do so. 
Appendix B: Informed Consent Form B

Project Title: Preconceptions of Novice ESL/EFL Teachers

Introduction

Participants are invited to take place in this study. The purpose of the study is to discover whether pre-service ESL teachers have preconceptions about ESL teaching and, if so, to discover the nature of those preconceptions.

Information about Participants' Involvement in the Study

Participants accepting the invitation to take part in this study will be interviewed by the investigators. The interviews will be taped and transcribed.

The transcriptions will be analyzed for patterns relating to teacher thinking. The tapes and transcripts will remain private and confidential. Both will be kept in a secure location in Claxton Addition at the College of Education, University of Tennessee. The results of the interviews and analysis will be presented in English 474 on December 6, 1999, and may be considered for eventual publication. No participant shall be mentioned by name in any written or oral presentation of the findings.

Participants will take part in one audio-taped interview lasting one half to one hour in Claxton 17, Claxton 21, or at an alternative location of the participant's choosing.

Risks

Though no serious risks to participants are anticipated, students may feel some discomfort due to the presentation of findings in the English 474 classroom. Again, all measure will be taken to assure confidentiality. Participants may voluntarily withdraw from the study if such feelings arise.

\section{Benefits}

This study may provide insights into ways teacher education can be further improved. The study addresses the need to understand and adjust potentially problematic preconceptions of ESL teachers that may undermine their effectiveness.

\section{Confidentiality}

Data gathered in this study will be kept confidential. Data will be stored securely and will be made available only to persons conducting the study unless participants specifically give permission in writing to do otherwise. The data will be stored in a locked filling cabinet in the College of Education for three years. Names will be changed or omitted to protect participant identity. If there is information that they prefer to keep in confidence or information that might jeopardize confidentiality, that information will be deleted from the transcripts in advance of the date of the first presentation of the results of the study (December 6, 1999) and subsequent presentation or publication. Permission to include all participants in such media is assumed unless a participant requests removal from the study. 


\section{Contact Information}

If you have questions at any time about the study or the procedures, (or you experience adverse effects as a result of participating in this study, ) you may contact the researcher, [Jenelle Reeves], at [17 Claxton Addition], and [(423) 974-4257]. If you have questions about your rights as a participant, contact the Compliance Section of the Office of Research at (423) 974-3466.

\section{Participation}

Your participation in this study is voluntary: you may decline to participate without penalty. If you decide to participate, you may withdraw from the study at anytime without penalty and without loss of benefits to which you are otherwise entitled. If you withdraw from the study before data collection is completed your data will be returned to you or destroyed.

\section{Consent}

I have read the above information. I have received a copy of this form. I agree to participate in this study.

Name of Participant (printed) Date

Participant's signature Date

Investigator's signature Date 